\title{
Modeling of off-feed periods caused by subacute acidosis in intensive lactating ruminants: Application to goats
}

\author{
M. Desnoyers, ${ }^{*} \dagger$ S. Giger-Reverdin, ${ }^{* 1}$ C. Duvaux-Ponter, ${ }^{*} \dagger$ and D. Sauvant ${ }^{*} \dagger$ \\ *INRA, UMR791 Physiologie de la Nutrition et Alimentation, 16 rue Claude Bernard, 75005 Paris, France \\ †AgroParisTech, 16 rue Claude Bernard, 75005 Paris, France
}

\begin{abstract}
Off-feed periods caused by subacute rumen acidosis are often observed in intensive ruminant production systems but appear in an unpredictable manner. The objectives of this paper were first, to study the influence of spontaneous off-feed periods due to bouts of acidosis on milk composition and on some rumen and blood parameters and second, to model the day-to-day variations in rumen $\mathrm{pH}$, dry matter intake (DMI), and milk production during these bouts of acidosis. Twentyfive spontaneous off-feed periods were detected in an experiment performed in 18 mid-lactating goats fed a high concentrate diet over 11 wk. Dry matter intake, milk production, and rumen $\mathrm{pH}$ were measured daily during the experiment, which allowed us to model the day-to-day evolution of these 3 parameters during spontaneous bouts of acidosis. Bouts started with a very rapid $\mathrm{pH}$ decrease $(1 \mathrm{~d})$ followed by several days of relatively high rumen $\mathrm{pH}(>6.5)$ before recovery of preacidosis values. The $\mathrm{pH}$ decrease was followed by a decrease in DMI, reaching a nadir around $2 \mathrm{~d}$ after the start of the episode, and a milk yield decrease, reaching a nadir $3 \mathrm{~d}$ after the beginning of the episode. The high rumen $\mathrm{pH}$ was caused by the relatively small decrease in daily chewing time during the decrease in DMI. Therefore, chewing time per unit of DMI increased, which probably increased the buffer supply per unit of DMI. Dry matter intake and milk yield needed around $20 \mathrm{~d}$ to recover to preacidosis values. Energy balance also decreased during DMI and milk yield decreases but recovered more rapidly than DMI and milk yield. However, energy balance cumulated from the start of the bout of acidosis remained negative for more than $10 \mathrm{~d}$. Milk composition and rumen and blood parameters were not measured daily and therefore could not be used in the modeling process. However, during off-feed periods, milk fat and protein contents were negatively correlated with DMI, whereas milk lactose content was positively
\end{abstract}

Received October 7, 2008.

Accepted March 31, 2009.

${ }^{1}$ Corresponding author: sylvie.giger-reverdin@agroparistech.fr correlated with DMI. Low DMI was also linked to low blood $\mathrm{pH}$, bicarbonates, and low rumen volatile fatty acids but high levels of plasma nonesterified fatty acids. This indicates that rumen fermentation was reduced and body reserves were mobilized during bouts of acidosis. This analysis showed that spontaneous bouts of acidosis in intensively reared dairy ruminants can have a great influence on animal production and health over at least $3 \mathrm{wk}$, and can thus represent an important economic loss.

Key words: off-feed, acidosis, modeling, dairy goat

\section{INTRODUCTION}

Off-feed periods caused by subacute rumen acidosis (SARA) are often detected in intensive ruminant production systems (Uhart and Carroll, 1967; Tremere et al., 1968) and can appear in an unpredictable manner. They represent an important economic loss for the farmers and can negatively affect future production and animal health. Acidosis is usually defined by mean rumen $\mathrm{pH}$ but this parameter cannot be considered a full descriptor of rumen acidosis (Dragomir et al., 2008). The causal role of highly digestible and low-fiber diets has been recognized for a long time (Uhart and Carroll, 1967; Tremere et al., 1968). However, different types of carbohydrates such as NDF (or its indigestible part) or NSC, which can influence acidosis to various extents, can be characterized and might have to be taken into account in diet formulation (Mertens, 1997; Beauchemin and Yang, 2005). The experimental study of spontaneous SARA is difficult because bouts of acidosis cannot be scheduled and studied in a balanced design. Therefore, acidosis has been frequently induced experimentally by a sudden ruminal supply of easily fermentable carbohydrates in steers (Brown et al., 2000), sheep (Krehbiel et al., 1995), cows (Keunen et al., 2002; Krause and Oetzel, 2005), or goats (Cao et al., 1987). However, the global syndrome could only be partially studied by this approach. Although erratic DMI was evoked in some situations of subacidosis (Nocek, 1997), the evolution of mean daily DMI and milk yield during episodes of SARA was seldom mentioned 
Table 1. Composition and analysis of the experimental diet

\begin{tabular}{lc}
\hline Item & \\
\hline Composition $(\%$ of DM) & \\
Grass hay & 35 \\
Sugar beet pulp & 15 \\
Concentrate blend ${ }^{1}$ & 50 \\
DM $(\%)$ & 63 \\
Net energy $(\mathrm{MJ} / \mathrm{kg}$ of DM) & 6.48 \\
PDIN $^{2}(\mathrm{~g} / \mathrm{kg}$ of DM) & 95 \\
PDIE $(\mathrm{g} / \mathrm{kg}$ of DM) & 103 \\
Analysis $\%$ of DM) & \\
NDF & 34.7 \\
ADF & 15.9 \\
Acid detergent lignin & 1.8 \\
Ash & 6.4 \\
CP & 12.7 \\
Ether extract & \\
Enzymatic starch & 1.3 \\
NSC & \\
Mean particle size $(\mathrm{d} 50, \mathrm{~cm})$ & 16.5 \\
\end{tabular}

${ }^{1} 25 \%$ wheat, $25 \%$ barley, $30 \%$ maize, $15 \%$ soybean meal, $3 \%$ molasses, and $2 \%$ mineral premix ( $8 \% \mathrm{P}, 25 \% \mathrm{Ca}, 4 \% \mathrm{Mg})$.

${ }^{2} \mathrm{PDIN}=$ true protein digested in the small intestine when fermentable $\mathrm{N}$ is limiting; PDIE = true protein digested in the small intestine when fermentable energy is limiting; PDIN and PDIE are calculated from the INRA tables (Baumont et al., 2007).

${ }^{3}$ Calculated as $(\mathrm{OM}-\mathrm{NDF}-\mathrm{CP}$ - ether extract).

(Keunen et al., 2002; Krause and Oetzel, 2005) and never precisely described. Only Schwartzkopf-Genswein et al. (2003) described rumen $\mathrm{pH}$ and daily DMI patterns during acute and subacute acidosis but only in one beef steer. Several mechanistic models of either rumen biochemistry (Lescoat et al., 1996) or intake regulation in ruminants (Mertens, 1996) have already been published. However, none of these studies actually considered the issue of modeling the SARA process. To progress in modeling the dynamic aspects of offfeed periods due to spontaneous SARA, it was decided to focus on the spontaneous off-feed periods that were observed during an experiment aimed at studying the influence of an acidogenic diet on feeding behavior and rumen digestion in lactating goats.

\section{MATERIALS AND METHODS}

\section{Animals and Housing}

Eighteen dairy goats in mid lactation (8 Saanen and 10 Alpine; including 12 cannulated goats) that had never been included in an experiment on acidosis were used. They were kept in $2 \mathrm{~m} \times 1 \mathrm{~m}$ individual pens during the experiment. The present study was carried out according to French legislation on animal experimentation in line with the European Convention for the Protection of Vertebrates used for Experimental and other Scientific Purposes (European Directive 86/609). The composition of the TMR offered is given in Table 1 .
Energy and nitrogen values of the diet were calculated according to the INRA tables (Baumont et al., 2007). Goats were fed twice daily after milking, in proportions of two-thirds at $1600 \mathrm{~h}$ and one-third at $0800 \mathrm{~h}$, according to the time interval between milkings. Quantities offered were adjusted weekly to ensure $10 \%$ refusals. Animals started receiving the experimental diet after 2 wk of adaptation to the individual pens and after 1 wk of dietary transition from a $20 \%$ concentrate diet to the experimental diet. They were fed the experimental diet for $11 \mathrm{wk}$.

\section{Experimental Measurements}

$B W$ and Production. Animals were weighed weekly. Amounts of feed offered and refusals were individually weighed daily. To correct data for the influence of BW, DMI was calculated daily in grams per kilogram of BW using the value of the last previous weighing (maximum interval of 1 wk). Milk yield (MY) was recorded on 5 of $7 \mathrm{~d}$ and was also calculated in grams per kilogram of BW. Milk fat, protein, and lactose contents (MFC, MPC, and MLC, respectively) were analyzed once a week on 2 successive milkings. Energy balance (EB) was calculated on 5 of $7 \mathrm{~d}$ according to the formula published by Sauvant et al. (2007) using the BW of the last previous weighing (maximum interval of $1 \mathrm{wk}$ ) and the milk composition of the last previous sampling (maximum interval of $1 \mathrm{wk}$ ). It was calculated in kilojoules per kilogram of BW.

Continuous Measurements. Starting 1 wk before the beginning of the experiment, each of the 12 cannulated goats was accustomed to wearing a coat and a leather halter. When measured, rumen $\mathrm{pH}$ was monitored continuously by a self-cleaning $\mathrm{pH}$ probe (accuracy $=0.01 \mathrm{pH}$ unit, Fisher Bioblock Scientific, Illkirch, France) fitted in the rumen through the cannula and linked to a portable device (Easy Log EL-2, Omega Engineering Inc., Stamford, CT; Brossard et al., 2003a), which was placed in one of the coat pockets. Recordings of $\mathrm{pH}$ were made every minute. Due to some technical problems, $\mathrm{pH}$ was not measured every day in every goat and a variable number of days was missing from each goat. When at least $21 \mathrm{~h}$ had been recorded for 1 goat and $1 \mathrm{~d}$, the mean daily $\mathrm{pH}$ value was calculated and used for the analysis. Chewing was recorded daily using a portable electronic system [APEC (Appareil Portatif pour l'Etude du Comportement) developed at INRA, Theix, France] fitted under the lower jaw and adapted from the one used by Brun et al. (1984). The recording device was placed in the other coat pocket. Data files from the APEC unit were analyzed using software written at INRA Theix (France), which classified chewing activity bouts as rumination, intake, or nibbling. These 
data allowed the calculation of the daily durations of chewing. The mastication index was calculated as the mean daily duration of chewing (min) per kilogram of DMI. The intake rate was calculated as the mean daily DMI (g) eaten per minute of daily intake.

Postfeeding Kinetics. Four sampling kinetics were performed every 2 to 3 wk. Sampling kinetics comprised collection of blood samples for the measurement of $\mathrm{pH}$, bicarbonates $\left(\mathrm{HCO}_{3}\right)$, and electrolytes $\left(\mathrm{Na}^{+}, \mathrm{K}^{+}\right.$, and $\mathrm{Cl}^{-}$) in whole blood; NEFA in plasma; and the collection of rumen samples for VFA and acetate to propionate ratio analyses. Samples were taken before the morning feeding and 2, 4, and $6 \mathrm{~h}$ thereafter. Electrolytic balance in blood $\left[(\mathrm{mmol} / \mathrm{L})=\mathrm{Na}^{+}+\mathrm{K}^{+}-\mathrm{Cl}^{-}\right]$was calculated. All parameters were averaged for sampling times 2,4 , and $6 \mathrm{~h}$ because the greatest effect on them was observed between 2 and $6 \mathrm{~h}$ after feeding.

\section{Detection of Off-Feed Periods Caused by Acidosis}

Daily changes in DMI and MY were used to detect off-feed periods related to bouts of acidosis. First, for each goat, days with a DMI or MY not included in the interval [mean; mean $-1.5 \times \mathrm{SD}$ ] (calculated for each goat) were selected. Second, days with a decrease in DMI between 2 consecutive days greater than $10 \mathrm{~g} /$ $\mathrm{kg}$ of BW were selected. Third, days with a mean $\mathrm{pH}$ $<6.0$ were also selected. Finally, a goat was considered as experiencing a perturbation if at least 2 parameters of $\mathrm{pH}, \mathrm{DMI}$, and MY were selected at the same time or during at least 2 consecutive days. The end of the bout was determined by the last selected days. For the 8 off-feed periods in which rumen $\mathrm{pH}$ and DMI data were available, the decrease in DMI occurred approximately on the day after the minimum $\mathrm{pH}$ value. Thus, when $\mathrm{pH}$ was available, the check-off day with the minimum $\mathrm{pH}$ value was considered as $\mathrm{d} 0$. If $\mathrm{pH}$ was not available, the check-off day for the DMI decrease was considered as d 1 . Days were labeled from -5 to 25 if $25 \mathrm{~d}$ after the start point were available. Days -5 to -1 are presented as the preperiod. Using this method, 25 episodes were selected that will henceforth be designated as SARA. Only 2 goats of 18 did not present any off-feed episodes. Ten goats showed 1 episode, 4 goats showed 2 episodes, 1 had 3 episodes, and 1 had 4 episode.

Eight episodes detected in 6 goats had almost complete daily kinetics of rumen $\mathrm{pH}$ ( 7 to $20 \mathrm{~d}$ available, 14 $\mathrm{d}$ on average) with a measured value at $\mathrm{d} 0$. They were pooled and called "group pH." To study the influence of the intensity of acidosis, the set of 25 detected episodes was divided into 3 groups of 8 or 9 episodes according to the importance of the mean DMI decrease during $\mathrm{d}$ 1 to 5 , represented by the nadir value expressed as the percentage of the preperiod DMI value: low (group 1:
$17.2 \pm 13.8 \%$ ), middle (group 2: $29.0 \pm 13.9 \%$ ), and high (group 3: $72.0 \pm 12.7 \%$ ). The 8 animals present in the group $\mathrm{pH}$ were also allocated to the 3 groups according to their decreases in DMI: 5 in group 3, 2 in group 2, and 1 in group 1 .

\section{Statistical Analysis}

All statistical analyses were performed with the GLM procedure of Minitab (version 12.2, 1995, Minitab Inc., State College, PA). A principal component analysis was performed using Minitab on the rumen and blood parameters measured during the $21 \mathrm{~d}$ of SARA bouts for which these parameters were measured. Dry matter intake was included in the principal component analysis.

A simple compartmental model was built using ModelMaker (version 3, Cherwell Scientific Ltd., Oxford, UK) to fit simultaneously the kinetics of daily variations in rumen $\mathrm{pH}, \mathrm{DMI}$, and MY. Adjustments of the model were also performed using ModelMaker software.

\section{RESULTS}

During the 11 wk of the experiment, 25 episodes of SARA were detected. The proportion of experimental days selected was $12 \%$. The proportion of experimental days used for modeling was $43 \%$.

\section{Mastication Index and Milk Composition}

For the parameters that were not measured daily, the number of observations was not sufficient to be included in the modeling process. Therefore, the most important of these parameters were studied in relation to one of the key variables: DMI, which was chosen because it is more closely related than MY to these parameters.

Figure 1 shows that within goats the mastication index (average $=344 \pm 111 \mathrm{~min} / \mathrm{kg}$ of DMI) was negatively correlated with DMI. In contrast, the relationship between DMI and the total duration of chewing was not significant. Intake rate (average $=6.1 \pm 2.2 \mathrm{~g}$ of DMI/min) was positively and curvilinearly related to DMI, emphasizing that a low intake rate is one of the determinants of a decrease in daily DMI. Milk composition was also significantly altered during a spontaneous episode of SARA (Figure 2). Milk fat content (average $=38.0 \pm 7.92 \mathrm{~g} / \mathrm{kg}$ ) was significantly increased as DMI decreased: $\mathrm{MFC}=47.3-0.24 \mathrm{DMI}[\mathrm{n}=91$, number of episodes (nepisode) $=25$, root mean square error $(\mathbf{R M S E})=5.2, P$-value of the DMI coefficient $\left(\boldsymbol{P}_{\text {coef }}\right)$ $=0.004]$. A similar relationship was observed for MPC (average $=32.6 \pm 3.75 \mathrm{~g} / \mathrm{kg}$ ) $: \mathrm{MPC}=35.6-0.07 \mathrm{DMI}$ ( $\mathrm{n}=91$, nepisode $\left.=25, \mathrm{RMSE}=2.1, P_{\text {coef }}=0.032\right)$. 


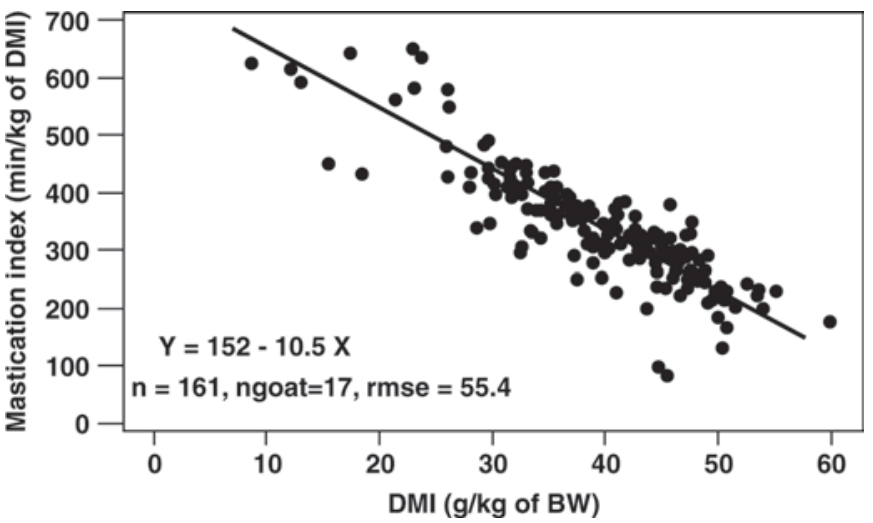

Figure 1. Relationship between mastication index and DMI during spontaneous bouts of acidosis observed in dairy goats. rmse $=$ root mean square error.

The within-goat regression slope was lower for MPC than for MFC; therefore, the milk fat to protein ratio increased as DMI decreased. In contrast, MLC (average $=48.2 \pm 2.90 \mathrm{~g} / \mathrm{kg}$ ) was positively correlated with DMI: MLC $=45.4+0.07$ DMI $(\mathrm{n}=83$, nepisode $=$ $\left.24, \mathrm{RMSE}=1.3, P_{\text {coef }}=0.001\right)$. For these 3 milk components, 1 observation had to be removed, because one of the goats had a DMI of only $2.4 \mathrm{~g} / \mathrm{kg}$ of BW and aberrant values for milk composition $(\mathrm{MFC}=101.8$, $\mathrm{MPC}=44.0$, and $\mathrm{MLC}=30.3 \mathrm{~g} / \mathrm{kg})$. However, the goat survived this severe off-feed episode.

The first axis of the principal component analysis explained more than half of the total variation (Figure 3 ) and indicated that low levels of DMI were associated with low blood $\mathrm{pH}$, electrolytic balance, and concentrations of $\mathrm{HCO}_{3}$. In contrast, low DMI was associated with an increase in NEFA, suggesting lipomobilization. Concentrations of VFA in the rumen were positively correlated with DMI and negatively correlated with the acetate to propionate ratio, indicating a low fermentation rate.

\section{Modeling Daily Kinetics of SARA Episodes}

Only the 8 episodes of group $\mathrm{pH}$ were used in the initial model. Mean daily values $( \pm \mathrm{SE}$ ) of rumen $\mathrm{pH}$, DMI, and MY are presented in Figure $4(\mathrm{pH})$ and Figure 5 (DMI and MY). Figure 4 shows that, after a preperiod in which $\mathrm{pH}$ was steady, it suddenly decreased at d 0 followed by a quick recovery period. The preperiod $\mathrm{pH}$ value was reached as soon as the next day (d 1). Moreover, during the following days, $\mathrm{pH}$ increased to a value greater than the mean preperiod value and then returned progressively, within $10 \mathrm{~d}$, to the initial preperiod value. Figure 5 shows that the decrease in DMI was more progressive and appeared to be delayed compared with that of $\mathrm{pH}$. The minimum was achieved around $\mathrm{d} 2$; however, the day of minimum rumen $\mathrm{pH}$ was observed to be variable between SARA episodes. The recovery of DMI was much smoother than that of $\mathrm{pH}$ and a rebound effect above the preperiod values was not observed. The preperiod level of DMI was obtained only after about d 18. The kinetics of MY also appeared to be delayed compared with that of DMI. The minimum value was observed at around $\mathrm{d} 3$, and

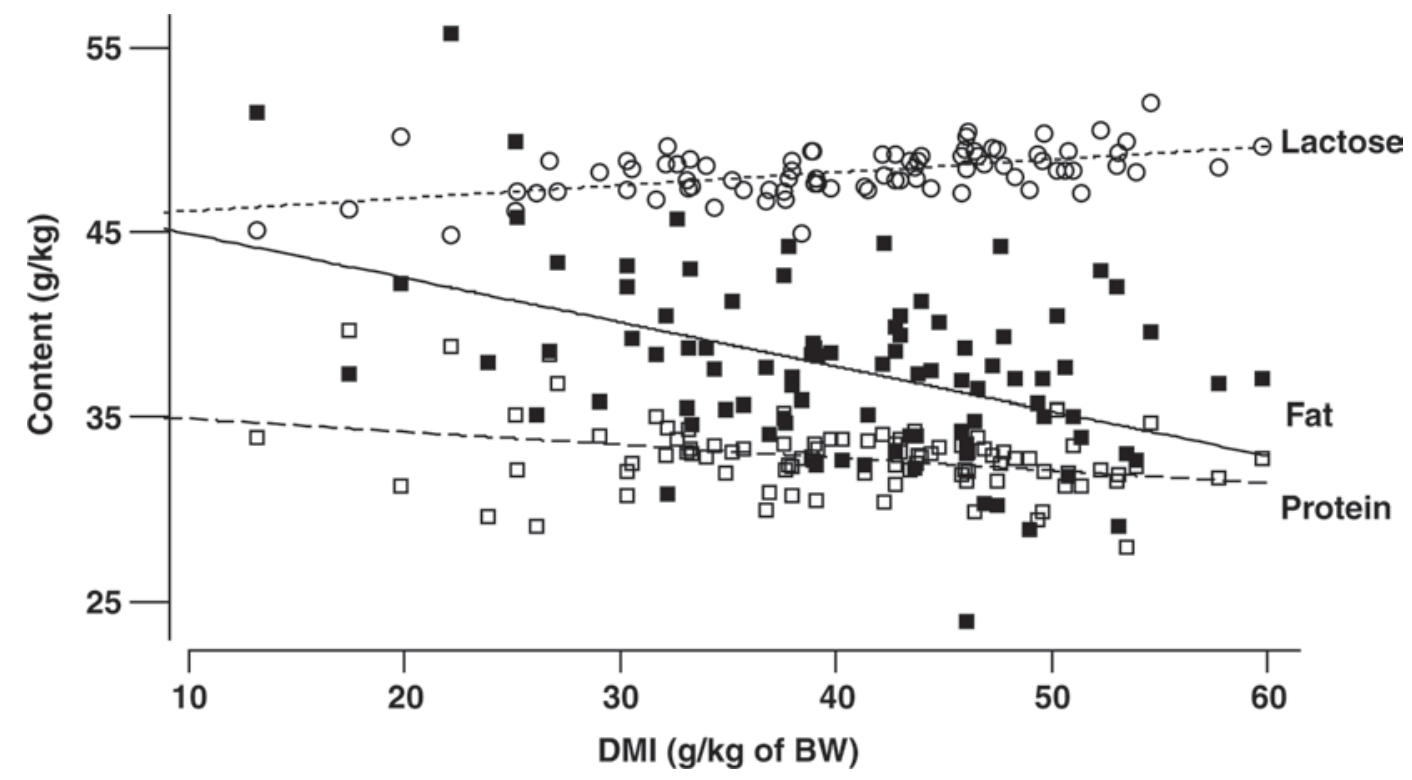

Figure 2. Within-goat relationship between milk composition and dry matter intake during spontaneous bouts of acidosis observed in dairy goats $(\bigcirc=$ milk lactose content, $\mathbf{\square}=$ milk fat content, $\square=$ milk protein content; equations in the text). 


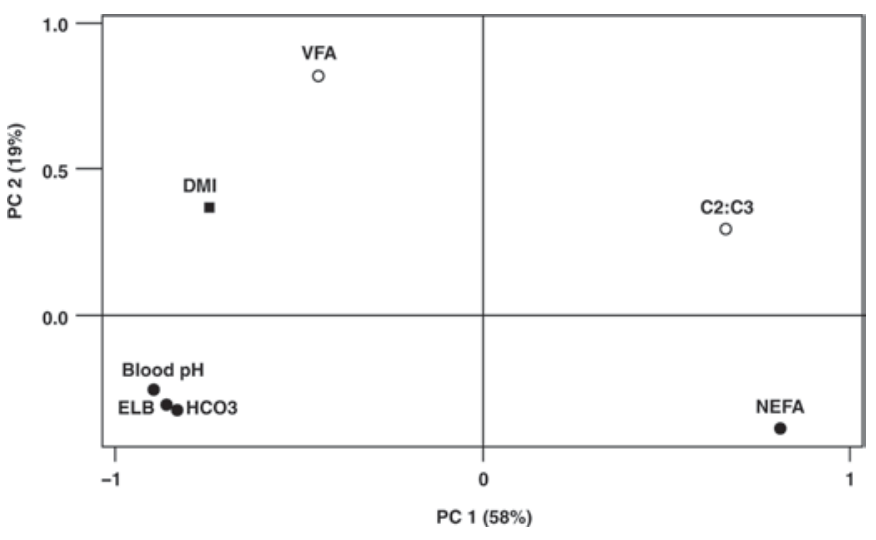

Figure 3. Correlations between the principal components $(\mathrm{PC})$ 1 and 2 and rumen parameters ( $\mathrm{O}$; VFA and $\mathrm{C} 2$ to $\mathrm{C} 3$ ratio); blood parameters $\left[\mathbf{\bullet} \mathrm{pH}\right.$, electrolytic balance (ELB), bicarbonates $\left(\mathrm{HCO}_{3}\right)$, and NEFA]; and DMI $(\mathrm{g} / \mathrm{kg}$ of $\mathrm{BW}, \mathbf{\square})$ during spontaneous bouts of acidosis observed in dairy goats.

the preperiod production level was not reached during the experimental period.

Figure 6 presents the diagram of the model. Differential equations and parameter definitions are presented in the appendix and parameter values are presented in Table 2. The basic principle consisted of building a dynamic compartmental structure providing waves of coordinated and successive disturbances (DIST in Figure 6) in pH, DMI, and MY. These waves were obtained by the transfer of a dimensionless quantity of matter through successive compartments (INIT, distpH, distDMI, distMY, and OutMY in Figure 6, with definitions as given below), according to mass action laws. An initial disturbance (modeled by a pulse in Figure 6) occurring after a preperiod of steady state induced the waves. The value of this initial pulse of matter was considered a priori proportional to the degree of severity of the disturbance and was pulsed into the initial (INIT) compartment. The INIT compartment transfers its matter into the $\mathrm{pH}$ disturbance compartment (DistPH), which in turn transfers its matter to the DMI disturbance compartment (DistDMI), which feeds the MY disturbance compartment (DistMY). This last transfer occurs after a delay. Finally, the DistMY compartment transmits its matter to a final compartment of accumulation (OutMY). The state variables of the compartments DistPH, DistDMI and DistMY are multiplied by scale parameters (aph, admi, and amy) and subtracted from the preperiod values of $\mathrm{pH}$ (pH0), DMI (DMI0), and MY (MY0) respectively, to obtain the simulation values. If only these successive events are used to build the model, the $\mathrm{pH}$ kinetics remains too low and a rebound effect is not observed. This is because the close and inverse relationship observed throughout the whole database between the level of DMI and the mastication index has not been taken into account in the simulation (Figure 1). The mastication index can be considered proportional to the saliva and buffers recycled per kilogram of DMI. Therefore, it was assumed that the $\mathrm{pH}$ rebound resulted from an intense bout of buffer recycling per unit DMI and a decrease in fermentable organic matter intake during the SARA episode. To include these aspects in the model, the $\mathrm{pH}$

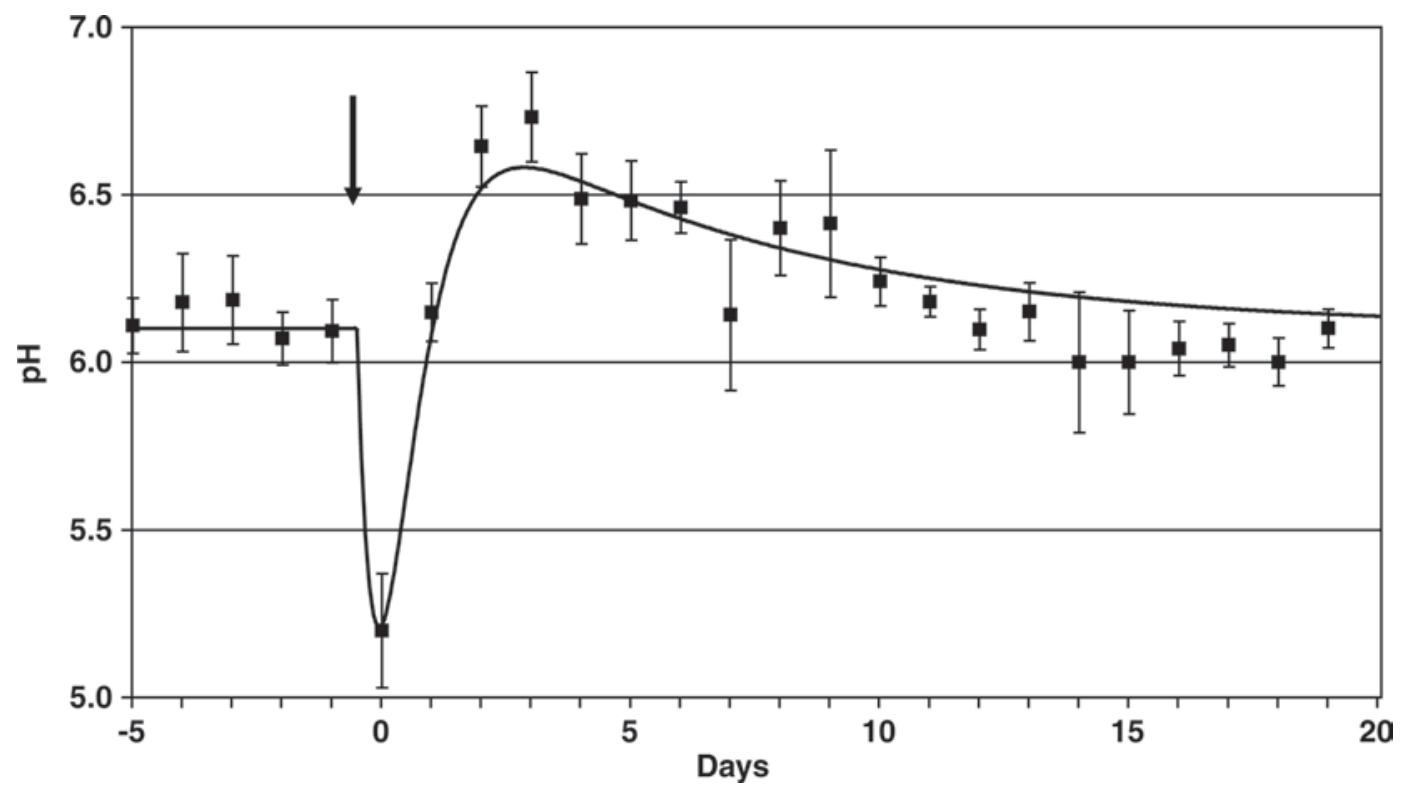

Figure 4. Evolution of rumen $\mathrm{pH}$ during spontaneous bouts of acidosis observed in dairy goats (observed values \pm SE; the continuous line represents the fitted model and the arrow the start of the episode). 


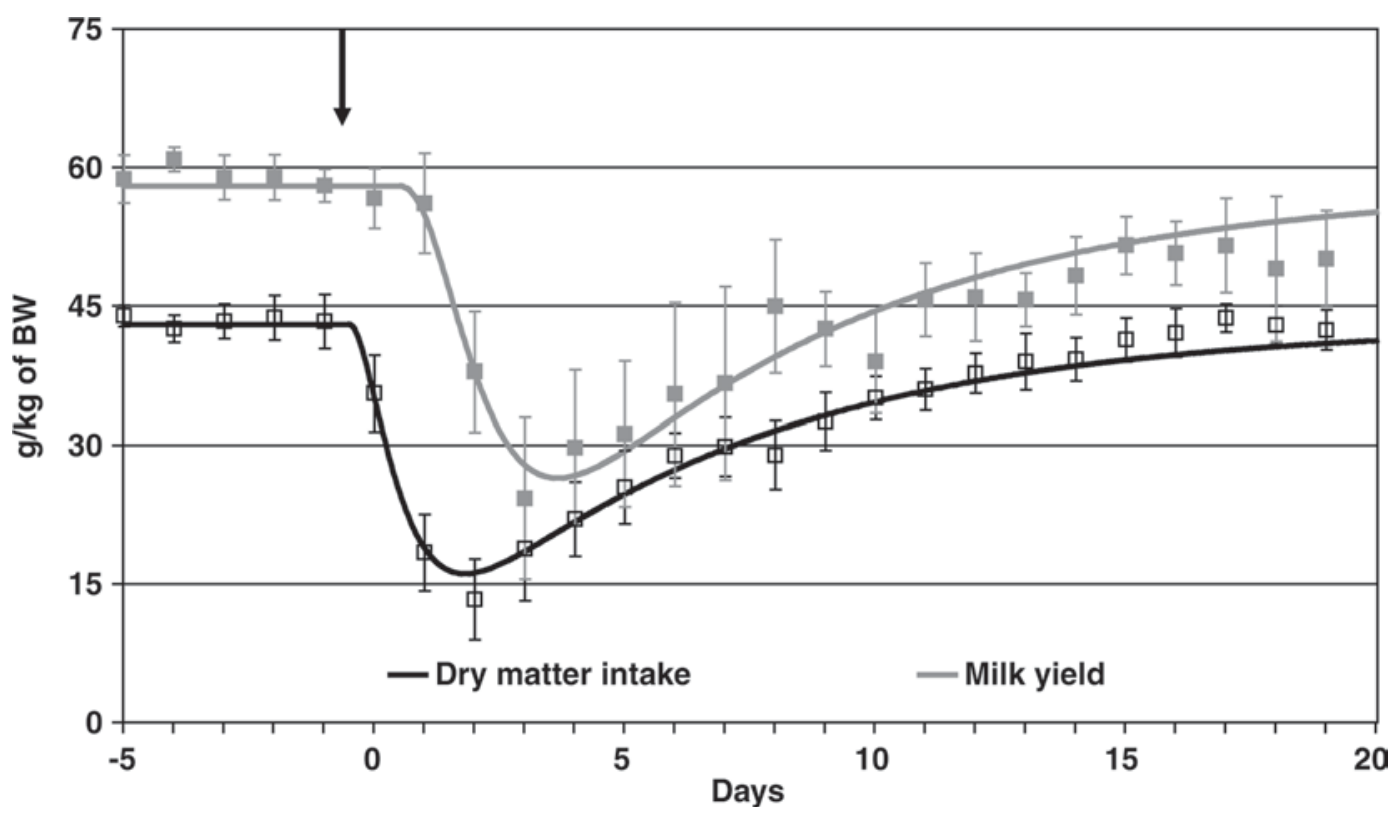

Figure 5. Evolution of intake (DMI) and milk yield (MY) during spontaneous bouts of acidosis observed in dairy goats (observed values \pm $\mathrm{SE}$; the continuous line represents the fitted model and the arrow the start of the episode).

value was represented as a function of both DistPH and DMI (Appendix). By doing this, a much more satisfactory response in $\mathrm{pH}$ kinetics was observed (continuous line in Figure 4).

In the present format, the model has to fit 15 parameters (Table 2 and Appendix). Fitting results are presented in Table 2 (first column) and in Figures 4 and 5 (continuous lines) together with the observed values (dots $\pm \mathrm{SE}$ ). As a first step, only the initial values of $\mathrm{pH}, \mathrm{DMI}$, and $\mathrm{MY}$ from $\mathrm{d}-5$ to -1 were calculated and then the 12 remaining values were fitted in several phases. The RMSE of the model adjustment was of 1.57. The adjusted time of the initial input (pulse value
$=421)$ was $108 \mathrm{~h}$. The minimum simulated values for $\mathrm{pH}, \mathrm{DMI}$, and MY occurred at $11 \mathrm{~h}(\mathrm{pHmin}=5.21)$, $56 \mathrm{~h}(\mathrm{DMImin}=15.6 \mathrm{~g}$ of DMI $/ \mathrm{kg}$ of BW), and $109 \mathrm{~h}$ after the initial pulse $(\mathrm{MYmin}=27.8 \mathrm{~g}$ of $\mathrm{MY} / \mathrm{kg}$ of $\mathrm{BW}$ ). Thus, the delay between minimum values of $\mathrm{pH}$ and DMI was $45 \mathrm{~h}$; it was $53 \mathrm{~h}$ between the minimum values of DMI and MY. After the initial adjustment, a final adjustment was performed to fit the 2 parameters (admieb and amyeb) applied to DMI and MY to estimate the kinetic of daily net EB. The kinetics of EB was also characterized by a decrease with a nadir on $\mathrm{d}$ 1 , followed by a recovery phase more rapid than that of DMI and MY. This phase meant that 0 was reached

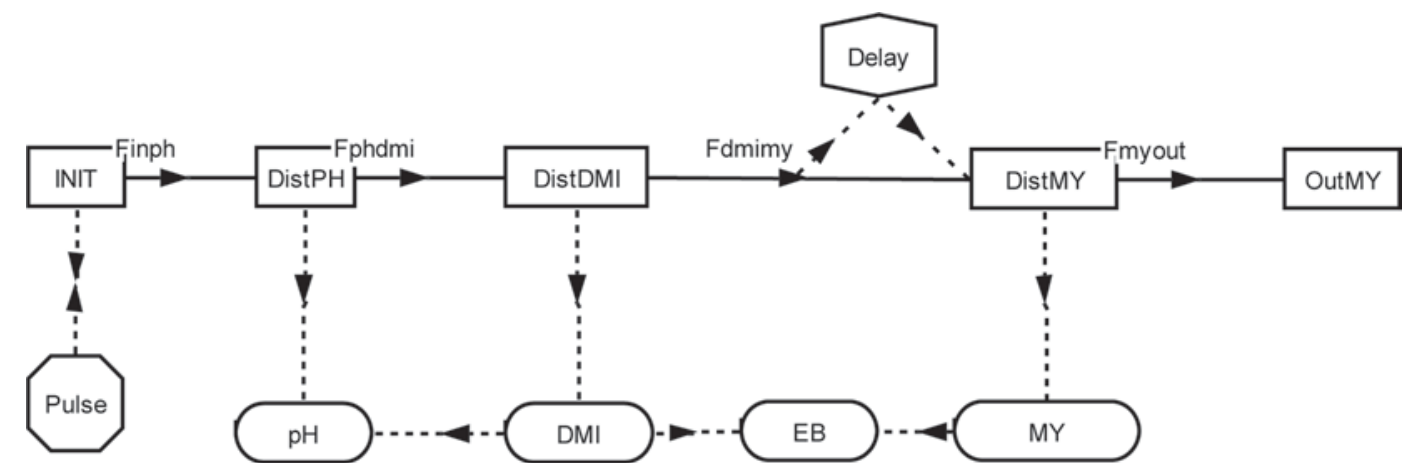

Figure 6. Diagram of the model showing the successive compartments of disturbances (Dist) used to model the evolution of the variables $\mathrm{pH}$, intake (DMI), milk yield (MY), and energy balance (EB) during spontaneous bouts of acidosis observed in dairy goats. The fluxes are represented by continuous arrows and are named using " $\mathrm{F}$ " followed by the names of the 2 affected compartments (rectangles $=$ compartments; ovals $=$ variables; solid arrows $=$ transfer of matter, dotted arrows $=$ transfer of information). Compartment and flux definitions are presented in the Appendix. INIT = initial compartment. 
Table 2. Values of the parameters adjusted for group $\mathrm{pH}$ and the 3 groups of bouts of acidosis differing by the intensity of the disturbance

\begin{tabular}{|c|c|c|c|c|}
\hline \multirow[b]{2}{*}{ Parameter $^{1}$} & \multirow[b]{2}{*}{ Group $\mathrm{pH}^{2}$} & \multicolumn{3}{|c|}{ Group $^{3}$} \\
\hline & & Group 3 & Group 2 & Group 1 \\
\hline pulse & 421 & 537 & 264 & 155 \\
\hline pulse time $(\mathrm{h})$ & 108 & 115 & 113 & 106 \\
\hline $\operatorname{kinph}(1 / \mathrm{h})$ & 0.006 & 0.007 & 0.009 & 0.005 \\
\hline kphdmi $(1 / \mathrm{h})$ & 0.074 & 0.084 & 0.112 & 0.095 \\
\hline kdmimy $(1 / h)$ & 0.076 & 0.080 & 0.124 & 0.078 \\
\hline delay (h) & 22.3 & 16.9 & 18.0 & 28.1 \\
\hline kmyout $(1 / \mathrm{h})$ & 0.061 & 0.060 & 0.116 & 0.059 \\
\hline aimast & 0.094 & 0.087 & 0.163 & 0.131 \\
\hline aph & 0.078 & 0.079 & 0.126 & 0.110 \\
\hline admi & 1.00 & 1.00 & 1.00 & 1.00 \\
\hline amy & 1.00 & 0.99 & 0.89 & 0.44 \\
\hline admieb & 2.02 & 2.02 & 2.38 & 1.97 \\
\hline amyeb & 1.47 & 1.43 & 1.57 & 1.45 \\
\hline pH0 & 6.10 & 6.15 & 6.06 & 5.97 \\
\hline DMI0 $(\mathrm{g} / \mathrm{kg}$ of BW) & 43 & 45 & 43 & 44 \\
\hline MY0 $(\mathrm{g} / \mathrm{kg}$ of $\mathrm{BW})$ & 58 & 65 & 60 & 54 \\
\hline $\mathrm{RMSE}^{4}$ & 1.57 & $2.61(3.16)$ & $1.93(3.27)$ & $1.80(1.84)$ \\
\hline
\end{tabular}

${ }^{1}$ Parameter definitions are in the Appendix.

${ }^{2}$ Eight bouts of acidosis with complete $\mathrm{pH}$ kinetics.

${ }^{3}$ Group 3: high disturbance; group 1: low disturbance

${ }^{4}$ The root mean square error (RMSE) obtained with the values of the parameters estimated for group $\mathrm{pH}$ are shown in parentheses, except the pulse one, which was adjusted.

around $\mathrm{d} 4$ and remained at an equilibrium until the end of the modeling period $(20 \mathrm{~d})$. Between $\mathrm{d} 0$ and $\mathrm{d}$ 10 , the cumulated $\mathrm{EB}$ was negative (average $=-481$ $\mathrm{kJ} / \mathrm{kg}$ of $\mathrm{BW})$.

\section{Modeling the Intensity of the Disturbance}

To assess the adaptability of the model to different levels of disturbance intensity, the 3 groups were used separately. Mean levels and standard errors of $\mathrm{pH}$, DMI, and MY were not different during the preperiod between the 3 groups. Differences between the 3 groups for MY were not significant because of the limited number of animals. However, the decrease in DMI (Drop$\mathrm{DMI}_{\text {preperiod to1-4 }}$ ) calculated between the mean DMI during the preperiod days and the minimum observed during d 1 to 4, was correlated with the mean MY level from $\mathrm{d}-5$ to $-1\left(\mathrm{MY}_{-5 \text { to- } 1}\right)$ : DropDMI $\mathrm{Dreperiod} \mathrm{to} 1-4=$ $0.30 \times \mathrm{MY}_{-5 \mathrm{to}-1}\left(\mathrm{n}=25, \mathrm{R}^{2}=0.2, \mathrm{RMSE}=11.8 \mathrm{~g} /\right.$ $\mathrm{kg}$ of BW). This indicates that SARA was more severe in high-producing goats compared with low-producing goats.

The previous model was fitted separately to the 3 groups for $\mathrm{pH}$, DMI, and MY. In the first phase, for each group, only the value of the initial pulse was adjusted, the other parameters being the same as for the previous adjustment (group $\mathrm{pH}$ ). After that, a second phase of fitting was undertaken to try to improve the RMSE. The values obtained are presented in columns labeled group 3 , group 2, and group 1 in Table 2 . When adjusting only the pulse value, the RMSE increased, especially for groups 2 and 3 . However, the improvement in RMSE was not large for groups 1 and 3 when all the parameters were adjusted. Moreover, the values for the adjusted parameters were of the same order of magnitude among the 3 groups. The only exception was "amy" (scale parameter between DistMY and MY values), which was smaller for group 1 than for the other two groups. This suggests that SARA had a lower effect on MY than on DMI for group 1 compared with the other 2 groups. Thus, except for MY0, there were no significant relationships between the pulse values and the values of the other adjusted parameters.

Figure 7 ( $a, b$, and c) presents the observed and simulated patterns of DMI, MY, and $\mathrm{pH}$ for the 3 groups, respectively. The minimum values observed for DMI and MY were systematically lower than the simulated ones. This suggests that a transitory mechanism could exist that amplified the decreases in DMI and MY beyond those accounted for by the model. During the $20 \mathrm{~d}$ of the modeled episodes, the decrease in MY, compared with the MY of the preperiod, was 5.3, 4.4, and 19.5 $\mathrm{g} / \mathrm{kg}$ of $\mathrm{BW}$ (or 10.0, 7.2, and $30.0 \%$ ) for animals in groups 1,2 and 3 , respectively.

A study focused on the 6 goats that experienced more than one SARA episode showed that the severity, calculated as the nadir value expressed as a percentage of the preperiod value, was lower for the second episode than for the first one $(21.0 \pm 10.7 \%$ vs. $57.4 \pm 29.5 \%$, respectively; $P=0.017$ ). 
(a)

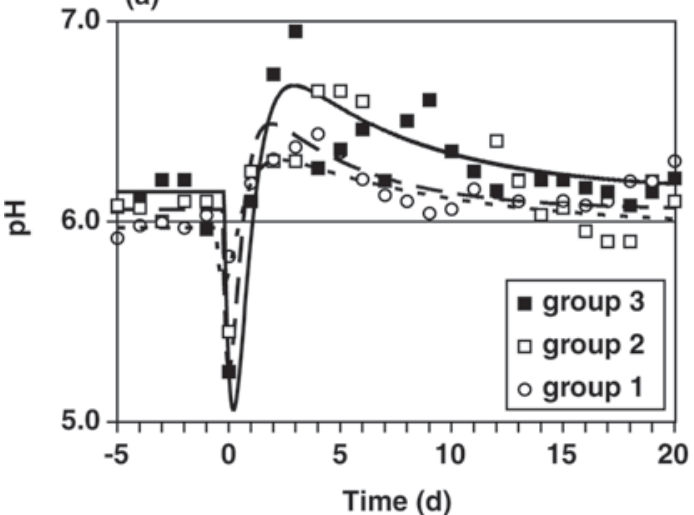

(c)

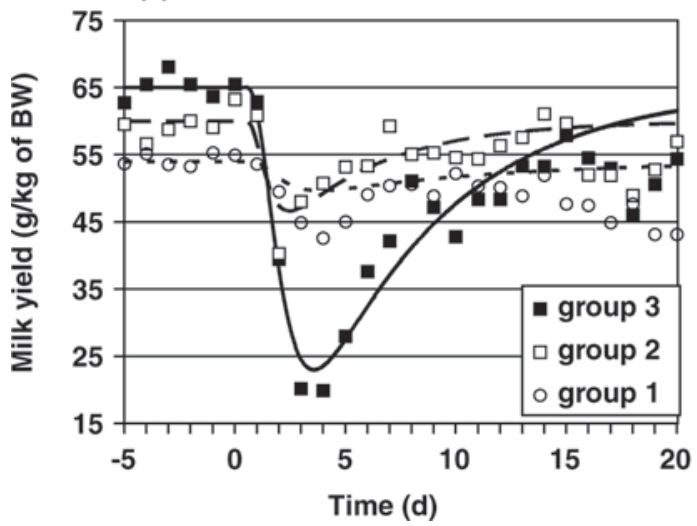

(b)

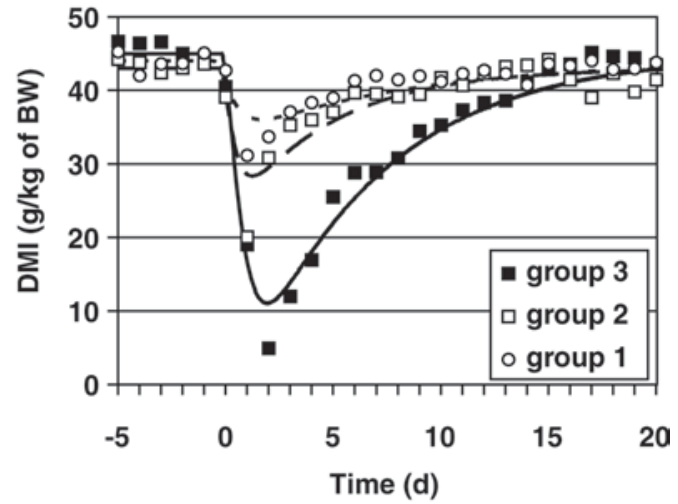

Figure 7. Evolution of a) pH, b) DMI, and c) milk yield (MY) for the 3 groups of bouts of acidosis observed in dairy goats and differing in the intensity of the disturbance (group 3 high to group 1 low). The marks are observed values, and the continuous line represents the fitted model.

\section{DISCUSSION}

Detection of bouts of SARA in this experiment was primarily based on decreases in intake and milk yield rather than on the measurement of low rumen $\mathrm{pH}$ values mainly because of the numerous days without sufficient rumen $\mathrm{pH}$ data. However, the 8 episodes including sufficient rumen $\mathrm{pH}$ data showed that these offfeed periods were induced by low rumen $\mathrm{pH}$ and were thus the outcome of subacute acidosis. Nevertheless, the mean value of rumen $\mathrm{pH}$ during the whole modeled period (6.2 for group $\mathrm{pH}$ ) was above the threshold value of 6.0 usually used in the determination of SARA (Nocek, 1997; Oetzel, 2000), and mean rumen $\mathrm{pH}$ for the group $\mathrm{pH}$ was $>6.4$ during $5 \mathrm{~d}$. It could thus be questionable to name these periods "bouts of acidosis." However, because the initial disturbance observed in these 8 episodes was the decrease in $\mathrm{pH}$, we assumed that these off-feed periods represent what really happens in herds experiencing subacute acidosis. Brugère (2003) described SARA as a state without any symptoms that directly suggest digestive disturbances or as a state in which ruminal $\mathrm{pH}$ plays a key role but does not show a characteristic decrease. Oetzel (2000) also observed that the main symptom of SARA was a decrease in DMI. Off-feed periods observed in the present experiment were therefore assumed to be spontaneous SARA episodes.

In the present experiment, goats received a TMR with a high proportion (65\% of DM) of components rich in energy (concentrate and sugar beet pulp). It is somewhat surprising that so many episodes of SARA were observed with a dietary NDF of $34.7 \%$, which is slightly above the current recommendations of 30 to $35 \%$ of DM (Sauvant et al., 1999). This could be because of the high energy content of the diet, particularly with $12.5 \%$ wheat, $12.5 \%$ barley, and $15 \%$ sugar beet pulp. These 3 feedstuffs are known to be acidogenic (GigerReverdin et al., 2002; Sauvant et al., 2006). Moreover, the geometric mean of particle size of the present diet was low $(1.80 \mathrm{~cm})$, which probably increased the risk of SARA (Sauvant, 2000).

Modeling the kinetics of SARA episodes suggests that several successive phases of disturbances and adaptations occur. Although the analysis is mainly based 
on 8 episodes, the quality of model fit indicates the relevance of the theoretical part of the model providing a framework for successive biological events following first-order processes through the 3 compartments of mixing: DistPH, DistDMI, and DistMY. Consequently, the current analysis represents a first step toward a better understanding of SARA episodes, and more studies based on more episodes will be necessary to confirm our findings. An interesting result from this model is that the value of the initial pulse is the only parameter that allows the integration of the severity of the episode. This suggests that the regulation process appeared to be similar, whatever the severity of the episode. Because of an insufficient number of measurements for some explicative variables; for example, milk composition or ruminal parameters, the present model remains largely empirical. However, the interesting relationships that were obtained between DMI and the aforementioned variables leads us to consider that it is a first step in building a more mechanistic model of spontaneous SARA episodes in ruminants fed highconcentrate diets. Daily measurements of mastication index and milk composition in further experiments will certainly allow the model to be improved by the addition of these parameters.

Subacute ruminal acidosis is generally observed with diets low in fiber and high in energy (Uhart and Carroll, 1967; Tremere et al., 1968) or with excessive highly fermentable carbohydrates (Krause and Oetzel, 2006). This is why SARA was often experimentally induced by a sudden rumen load of rapidly fermentable carbohydrates (Brown et al., 2000; Keunen et al., 2002; Krause and Oetzel, 2005). In our experiment, the initial cause of SARA appeared to be located in the rumen and resulted in an abrupt $\mathrm{pH}$ decrease. The challenge is to find out more precisely what were the initial digestive or behavioral disturbances at the origin of spontaneous SARA episodes and to try to define indexes predicting the probability, and possibly the severity, of a SARA episode. Krause and Oetzel (2006) reported that total DMI was a major determinant of rumen $\mathrm{pH}$, but in our experiment the level of DMI was not related to the severity of the episode. The only factor that can be cited is the level of MY before SARA. Even if the differences in MY between the 3 groups were not significant, high-producing cows had a larger decrease in DMI and a higher initial pulse value than low milk producers.

The daily kinetics of rumen $\mathrm{pH}$ during spontaneous bouts of SARA showed a sudden decrease at d 0 , followed by a very quick recovery within a day, and thereafter a clear rebound with high values of $\mathrm{pH}(>6.5)$. In contrast, experimentally induced SARA with high quantities of rapidly fermentable carbohydrates (more than $12 \mathrm{~g} / \mathrm{kg}$ of BW) induced $\mathrm{pH}$ kinetics that did not involve a rebound $>6.5$, and they generally required more than $100 \mathrm{~h}$ to gradually return to initial values (Patra et al., 1996; Mohamed Nour et al., 1999; Brown et al., 2000). This large difference in the pattern of $\mathrm{pH}$ recovery shows that experimentally induced SARA is not representative of spontaneous SARA. The present pattern of rumen $\mathrm{pH}$ with a rebound above 6.5 , which seemed to be characteristic of spontaneous acidosis bouts, was rarely described in the literature. It has been shown only in 1 growing animal (SchwartzkopfGenswein et al., 2003) and 2 adult sheep (Kezar and Church, 1979) but it has never been described in lactating animals. At least two basic homeostatic mechanisms seem to be involved in $\mathrm{pH}$ rebound and recovery. The first is a decrease in DMI and thus in the supply of fermentable matter to rumen microorganisms. The positive relationship between DMI and VFA concentration on the first principal component strengthens this assumption. This decrease in VFA could also be explained by a decrease in microbial fermentation activity, which has already been observed during SARA (Martin et al., 2006). Second, there was an increase in the mastication index, and thus in the buffer recycled per DMI. This was the consequence of a relatively small decrease in the time spent chewing each day compared with the decrease in DMI. Individual variations in the mastication index are known to be negatively correlated with rumen pH (Giger-Reverdin et al., 2004). The clear rebound in rumen $\mathrm{pH}$ was probably the outcome of at least these two adaptations and allowed the animal to counteract the effect of acidosis.

It is usually assumed that DMI starts to be significantly depressed when rumen $\mathrm{pH}$ reaches 5.5 (Fulton et al., 1979; Oetzel, 2003). However, several hypotheses have been formulated to explain the relationship between rumen $\mathrm{pH}$ and DMI; for example, a decrease in the frequency and amplitude of ruminal contractions inducing a relative increase in rumen load (Braun et al., 1992; Oetzel, 2000), an increase in rumen lactic acid (Buéno, 1975) and in osmotic pressure (Oetzel, 2003; Martin et al., 2006), an inflammation of the ruminal epithelium (Oetzel, 2003), metabolic dehydration (see review by Krause and Oetzel, 2006), a decrease in the blood bicarbonate reserve (Krehbiel et al., 1995), or more generally an alteration in the metabolic acid-base status (Braun et al., 1992; Peyraud and Apper-Bossard, 2006). The present data confirmed the link between acid-base status and DMI as indicated by the position of the electrolytic balance and DMI on the first component of the principal component analysis. Milk yield is known to be strongly linked to DMI, and the pattern of milk yield decrease followed by a progressive recovery phase during an episode of SARA has already been described (Krause and Oetzel, 2005). 
The global delay in the whole episode of SARA is essentially controlled by the kinetics of the INIT compartment, which presents a mean residence time (inverse of fractional outflow rate) of $167 \mathrm{~h}$ (group $\mathrm{pH}$ ). Other structural delays are related to the mean residence time of matter in mixing compartments DistpH (13.5 h), DistDMI (13.2 h), and DistMY (16.4 h). The linear delay $(22.3 \mathrm{~h}$ for group $\mathrm{pH})$, which had to be added between the DistDMI and DistMY compartments, could be the result of transient stored energy utilization. The whole system globally has a mean residence time of around $9 \mathrm{~d}$. The delay between $\mathrm{pH}$, DMI, and MY decreases was only evoked in a few studies after induced SARA. Between $\mathrm{pH}$ and DMI, the delay was around 4 to $12 \mathrm{~h}$ in sheep (Kezar and Church, 1979; Patra et al., 1996) and around 1 to $2 \mathrm{~d}$ in a growing steer after 2 consecutive days of low rumen $\mathrm{pH}$ (Schwartzkopf-Genswein et al., 2003). Concerning milk yield, only Agenas et al. (2003) described a decrease in milk yield $24 \mathrm{~h}$ after induced feed deprivation. Some of the episodes in group 3 led to almost no intake over a few days, which might be compared with feed deprivation. However, as far as we are aware, these delays have not been precisely described and modeled until now. The delayed decrease in MY after that of DMI suggests a homeostatic adaptation to the shortage in available energy in the organism. The fact that the decrease in energy balance was approximately synchronized with those of DMI and MY is consistent with this assumption. Therefore, it can be assumed that DMI is the driving force in the decrease in MY in the first phase of an episode of SARA.

In the present experiment, $\mathrm{pH}, \mathrm{DMI}$, and MY needed around 10,18 , and more than $25 \mathrm{~d}$, respectively, to return to preperiod values. In contrast, in the experiment of Kezar and Church (1979), sheep needed between 48 and $96 \mathrm{~h}$ to reach an intake similar to that before induction of acidosis. Brossard et al. (2003b) also observed a reduction in DMI during the first 2 to $3 \mathrm{~d}$ after a change in diet in feed-restricted sheep. This is a lot less than what was observed in our experiment, but our results could be specific to dairy animals. The slow rate of recovery of DMI and MY compared with that of rumen $\mathrm{pH}$ raises a major issue. It is not clear whether DMI, MY, or another parameter is the driving force of the recovery phase. The energy balance recovered more rapidly (4 d) than DMI and MY. In contrast, the cumulated energy balance was systematically negative during SARA episodes and thus resulted in a large deficit. Apparently, this deficit was unable to induce a compensatory increase in DMI. Thus, homeostatic regulation of DMI appeared to have been overwhelmed by another mechanism. An aversion of the animal toward its diets is an assumption that is strengthened by the decrease in intake rate observed in the goats presenting the lowest level of DMI. This aversion could also explain why the minimum values observed for DMI and MY were systematically lower than the simulated ones. The fact that the second bout of acidosis is always more limited than the first suggests a kind of memory of the organism confronted with a new acidosis challenge, which is consistent with this hypothesis. However, all these aspects need to be confirmed in additional experiments.

It is well documented that high-concentrate diets cause low milk fat (Peyraud and Apper-Bossard, 2006). However, during a SARA episode, milk fat was significantly higher after the initial decrease in rumen $\mathrm{pH}$ than during the preperiod. The higher milk fat content and the differences in the slopes of milk fat and protein contents are likely the outcome of lipomobilization. There is actually a period of intense lipomobilization during bouts of SARA, which is confirmed by our results and those of Brown et al. (2000), in which plasma NEFA are raised. Generally, as dietary NDF or concentrate is modified, the variation in milk fat content is opposite to those of milk protein and lactose (Sauvant, 1999). This was not the case during bouts of SARA, in which milk fat and protein content responses were opposite to that of lactose. These data suggest that lactose secretion is depressed because of the rapid shortage in propionate coming from the rumen and the limited possibility for endogenous gluconeogenesis in lactating ruminants. The present data on rumen VFA and acetate to propionate ratio are consistent with this assumption. As lactose secretion constitutes the major driving force of milk water secretion, its decrease induces the decrease in MY, which induces a concentration of milk components and therefore an increase in milk fat and protein contents. Such a phenomenon of milk concentration has previously been observed in experimentally starved lactating cows (Drackley et al., 1992). Finally, both lipomobilization and milk concentration likely induced the increase in milk fat content.

\section{CONCLUSIONS}

Subacute ruminal acidosis is an important determinant of ruminant productivity. A systematic study of individual spontaneous episodes of SARA provided a precise description of their kinetics and allowed them to be modeled. The kinetics of a SARA bout were characterized by a rapid modification in $\mathrm{pH}$ followed by waves of disturbances in DMI and MY and a progressive recovery phase. The SARA episodes lasted around 20 d. Today, many aspects of the mechanisms behind the induction of bouts of acidosis and recovery remain unknown and this model represents a first step in building a mechanistic model of SARA episodes in ruminants 
fed high-concentrate diets. The current results illustrate the dividing line between physiology and pathology and the role of homeostatic processes in saving the animal's life, as it seems that animals might possess some nutritional wisdom. It can be assumed that death would occur if compensatory mechanisms, mainly a decrease in DMI, do not initiate quickly enough because of the delay that is shown in the current work, or when the aversion toward the diet remains higher than hunger over a long period.

Considering the long duration of the SARA episodes described in this paper (almost $20 \mathrm{~d}$ ) and the frequency of this disease, it is necessary to evaluate the influence of diets rich in concentrate, not only on mean values of chewing activity and milk production, but also on the occurrence and severity of bouts of SARA. It also seems obvious from these results that the occurrence of bouts of acidosis has to be analyzed in all experiments involving high-concentrate diets or high-producing animals, because whatever the parameter tested, the effects of using high-concentrate diets can be confounded with the acidosis effect.

\section{ACKNOWLEDGMENTS}

The authors gratefully acknowledge Alltech Inc. (Lexington, KY) for their financial support of this project; A. Aymard, J. Chevallier, O. Dhumez, G. Durandet, M. Langot, P. Piquerel, A. Severin, and J. Tessier (INRA, UMR 791 Physiologie de la Nutrition et Alimentation, Paris and Thiverval-Grignon, France) for their technical assistance during the experiment; and A. A. Ponter (Ecole Nationale Vétérinaire d'Alfort, Maisons-Alfort, France) for rereading the manuscript.

\section{REFERENCES}

Agenas, S., K. Dahlborn, and K. Holtenius. 2003. Changes in metabolism and milk production during and after feed deprivation in primiparous cows selected for different milk fat content. Livest. Prod. Sci. 83:153-164.

Baumont, R., J. P. Dulphy, D. Sauvant, G. Tran, F. Meschy, J. Aufrère, J. L. Peyraud, and P. Champciaux. 2007. Les tables de la valeur des aliments. Pages 181-286 in Alimentation des bovins, ovins et caprins. Besoin des animaux-Valeurs des aliments. Tables INRA 2007. Quae ed. INRA, Paris, France.

Beauchemin, K. A., and W. Z. Yang. 2005. Effects of physically effective fiber on intake, chewing activity, and ruminal acidosis for dairy cows fed diets based on corn silage. J. Dairy Sci. 88:21172129 .

Braun, U., T. Rihs, and U. Schefer. 1992. Ruminal lactic acidosis in sheep and goats. Vet. Rec. 130:343-349.

Brossard, L., M. Fabre, C. Martin, and B. Michalet-Doreau. 2003a. Validation of continuous ruminal $\mathrm{pH}$ measurements by indwelling probes. Page 25 in Proc 26th Conference on Gastrointestinal Function, Chicago, IL. Department of Animal Science, Michigan State University, East Lansing.

Brossard, L., C. Martin, and B. Michalet-Doreau. 2003b. Ruminal fermentative parameters and blood acido-basic balance changes during the onset and recovery of induced latent acidosis in sheep. Anim. Res. 52:513-530.
Brown, M. S., C. R. Krehbiel, M. L. Galyean, M. D. Remmenga, J. P. Peters, B. Hibbard, J. Robinson, and W. M. Moseley. 2000. Evaluation of models of acute and subacute acidosis on dry matter intake, ruminal fermentation, blood chemistry, and endocrine profiles of beef steers. J. Anim. Sci. 78:3155-3168.

Brugère, H. 2003. Physiopathologie de l'acidose latente du rumen. Pages 5-26 in Proc. Actualités en pathologie bovine. Ecole Nationale Vétérinaire d'Alfort, Maisons-Alfort, France.

Brun, J. P., S. Prache, and G. Béchet. 1984. A portable device for eating behaviour studies. Pages 1-8 in Proc. 5th European Grazing Workshop, Edinburgh, UK. Hill Farming Association, Midlothian, UK.

Buéno, L. 1975. Rôle de l'acide DL-lactique dans le contrôle de l'ingestion alimentaire chez le mouton. Ann. Rech. Vet. 6:325-335.

Cao, G. R., P. B. English, L. J. Filippich, and S. Inglis. 1987. Experimentally induced lactic acidosis in the goat. Aust. Vet. J. 64:367-370

Drackley, J. K., M. J. Richard, D. C. Beitz, and J. W. Young. 1992 Metabolic changes in dairy cows with ketonemia in response to feed restriction and dietary 1,3-butanediol. J. Dairy Sci. 75:16221634

Dragomir, C., D. Sauvant, B. Michalet Doreau, J. L. Peyraud, and S Giger-Reverdin. 2008. Meta-analysis of $0-8$ hours post-prandial kinetics of ruminal $\mathrm{pH}$. Animal 2:1437-1448.

Fulton, W. R., T. J. Klopfenstein, and R. A. Britton. 1979. Adaptation to high concentrate diets by beef cattle. 2 . Effect of ruminal $\mathrm{pH}$ alteration on rumen fermentation and voluntary intake of wheat diets. J. Anim. Sci. 49:785-789.

Giger-Reverdin, S., C. Duvaux-Ponter, D. Sauvant, O. Martin, I Nunes do Prado, and R. Müller. 2002. Intrinsic buffering capacity of feedstufs. Anim. Feed Sci. Technol. 96:83-102.

Giger-Reverdin, S., D. Sauvant, J. Tessier, G. Bertin, and P. MorandFehr. 2004. Effect of live yeast culture supplementation on rumen fermentation in lactating dairy goats. S. Afr. J. Anim. Sci 34(Suppl. 1):59-61.

Keunen, J. E., J. C. Plaizier, I. Kyriazakis, T. F. Duffield, T. M. Widowski, M. I. Lindinger, and B. W. McBride. 2002. Effects of a subacute ruminal acidosis model on the diet selection of dairy cows. J. Dairy Sci. 85:3304-3313.

Kezar, W. W., and D. C. Church. 1979. Ruminal changes during the onset and recovery of induced lactic acidosis in sheep. J. Anim. Sci. 49:1161-1167.

Krause, K. M., and G. R. Oetzel. 2005. Inducing subacute ruminal acidosis in lactating dairy cows. J. Dairy Sci. 88:3633-3639.

Krause, K. M., and G. R. Oetzel. 2006. Understanding and preventing subacute ruminal acidosis in dairy herds: A review. Anim. Feed Sci. Technol. 126:215-236.

Krehbiel, C. R., R. A. Britton, D. L. Harmon, T. J. Wester, and R. A. Stock. 1995. The effects of ruminal acidosis on volatile fatty acid absorption and plasma activities of pancreatic enzymes in lambs. J. Anim. Sci. 73:3111-3121.

Lescoat, P., A. Danfaer, and D. Sauvant. 1996. Discussion of methods in building and validating a model: Example of amino acid metabolism in ruminants. Ann. Zootech. 45(Suppl.):237-255.

Martin, C., L. Brossard, and M. Doreau. 2006. Mécanismes d'apparition de l'acidose ruminale latente et conséquences physiopathologiques et zootechniques. Prod. Anim. 19:93-108.

Mertens, D. R. 1996. Methods in modelling feeding behaviour and intake in herbivores. Ann. Zootech. 45(Suppl.):153-164.

Mertens, D. R. 1997. Creating a system for meeting the fiber requirements of dairy cows. J. Dairy Sci. 80:1463-1481.

Mohamed Nour, M. S., M. T. Abusamra, and B. E. D. Hago. 1999. Experimentally induced lactic acidosis in Nubian goats: Clinical, biochemical and pathological investigations. Small Rumin. Res. 31:7-17.

Nocek, J. E. 1997. Bovine acidosis: Implications on laminitis. J. Dairy Sci. $80: 1005-1028$

Oetzel, G. R. 2000. Clinical aspects of ruminal acidosis in dairy cattle. Pages 46-53 in Proc. 33rd Annu. Conf. Am. Assoc. Bovine Pract., Rapid City, SD. Am. Assoc. Bovine Pract., Columbus, OH. 
Oetzel, G. R. 2003. Introduction to ruminal acidosis in dairy cattle. Preconvention Seminar 7: Dairy Herd Problem Investigation Strategies. 36th Annu. Conf. AABP, Columbus, OH. Am. Assoc. Bovine Pract., Columbus, OH.

Patra, R. C., S. B. Lal, and D. Swarup. 1996. Biochemical profile of rumen liquor, blood and urine in experimental acidosis in sheep. Small Rumin. Res. 19:177-180.

Peyraud, J. L., and E. Apper-Bossard. 2006. L'acidose latente chez la vache laitière. Prod. Anim. 19:79-92.

Sauvant, D. 1999. Le concept des lois de réponses multiples aux régimes, trait d'union entre les domaines techniques et économiques de l'élevage. Pages 11-17 in 6èmes Rencontres autour des Recherches sur les Ruminants, Paris. INRA and Institut de l'Elevage, Paris, France.

Sauvant, D. 2000. Granulométrie des rations et nutrition du ruminant. Prod. Anim. 13:99-108.

Sauvant, D., S. Giger-Reverdin, and F. Meschy. 2006. Le contrôle de l'acidose ruminale latente. Prod. Anim. 19:69-78.

Sauvant, D., S. Giger-Reverdin, and F. Meschy. 2007. Alimentation des caprins. Pages 137-148 in Alimentation des bovins, ovins et caprins. Besoin des animaux - Valeurs des aliments. Tables INRA 2007. Quae ed. INRA, Paris, France.

Sauvant, D., F. Meschy, and D. Mertens. 1999. Les composantes de l'acidose ruminale et les effets acidogènes des rations. Prod. Anim. $12: 49-60$.

Schwartzkopf-Genswein, K. S., K. A. Beauchemin, D. J. Gibb, D. H. Crews, D. D. Hickman, M. Streeter, and T. A. McAllister. 2003. Effect of bunk management on feeding behavior, ruminal acidosis and performance of feedlot cattle: A review. J. Anim. Sci. 81(E Suppl. 2): E149-E158.

Tremere, A. W., W. G. Merrill, and J. K. Loosli. 1968. Adaptation to high concentrate feeding as related to acidosis and digestive disturbances in dairy heifers. J. Dairy Sci. 51:1065-1072.

Uhart, B. A., and F. D. Carroll. 1967. Acidosis in beef steers. J. Anim. Sci. 26:1195-1198.

\section{Appendix: Description of the Model Parameters}

The model is built as a dynamic compartmental structure providing waves of coordinated and successive disturbances (DIST). Differential equations are presented below and parameters values are given in Table 2.

Initial Compartment: INIT

$$
\mathrm{dINIT} / \mathrm{dt}=\text { Pulse (pulse, tpulse })- \text { Finph }
$$

$$
\text { Finph }=\text { kinph } \times \text { INIT }
$$

kinph: fractional outflow rate from INIT to DistPH

pulse: initial pulse of dimensionless

matter occurring at tpulse

\section{Compartment Disturbance of $\mathrm{pH}$ : DistPH}

$$
\begin{gathered}
\mathrm{dDistPH} / \mathrm{dt}=- \text { Fphdmi }+ \text { Finph } \\
\text { Fphdmi }=\text { kphdmi } \times \text { DistPH }
\end{gathered}
$$

kphdmi: fractional outflow rate from DistPH to DistDMI

\section{Compartment Disturbance of DMI: DistDMI}

$$
\begin{gathered}
\mathrm{dDistDMI} / \mathrm{dt}=+ \text { Fphdmi }- \text { Fdmimy } \\
\text { Fdmimy }=\text { kdmimy } \times \text { DistDMI } \\
\text { kdmimy: fractional outflow rate } \\
\text { from DistDMI to DistMY }
\end{gathered}
$$

\section{Compartment Disturbance of MY: DistMY}

$$
\begin{gathered}
\mathrm{dDistMY} / \mathrm{dt}=- \text { Fmyout }+ \text { Delay } \\
\text { Fmyout }=\text { kmyout } \times \text { DistMY } \\
\text { kmyout: fractional outflow rate } \\
\text { from DistMY to OutMY }
\end{gathered}
$$

Delay: delay applied to Fdmimy

\section{Compartment of MY Accumulation: OutMY}

$$
\operatorname{doutMY} / \mathrm{dt}=+ \text { Fmyout }
$$

\section{Variable $\mathrm{pH}$}

$$
\begin{aligned}
& \mathrm{pH}=\mathrm{pH} 0-(\operatorname{aph} \times \text { DistPH }) \\
& +[\text { aimast } \times(\mathrm{DMI} 0-\mathrm{DMI})]
\end{aligned}
$$

aph: size parameter between DistPH and actual $\mathrm{pH}$ value

aimast: parameter representing mastication index variations

pH0: mean value of $\mathrm{pH}$ during the preperiod

$$
(\mathrm{d}-5 \text { to }-1)
$$

DMI0: mean value of DMI during the preperiod

$$
\text { (d }-5 \text { to }-1)
$$


Variable DMI (g/kg of BW)

$$
\text { DMI }=\text { DMI0 }(\operatorname{admi} \times \text { DistDMI })
$$

admi: size parameter between DistDMI and DMI value (admi is arbitrarily set to 1.00 )

DMI0: mean value of DMI during the preperiod

$$
\text { (d }-5 \text { to }-1)
$$

Variable: $M Y(\mathrm{~g} / \mathrm{kg}$ of $B W)$

$$
\mathrm{MY}=\mathrm{MY0}-\text { amy } \times \text { DistMY }
$$

amy: size parameter between DistMY and MY value
MY0: mean value of MY during the preperiod

$$
(\mathrm{d}-5 \text { to }-1)
$$

\section{Variable: EB (kcal/kg of BW)}

$$
\mathrm{EB}=\text { admieb } \times \mathrm{DMI}-\text { amyeb } \times \mathrm{MY}
$$

admieb: size parameter between DMI and EB, this parameter represents the dietary energy amyeb: size parameter between MY and EB, this parameter represents the proportion of energy required for milk production 